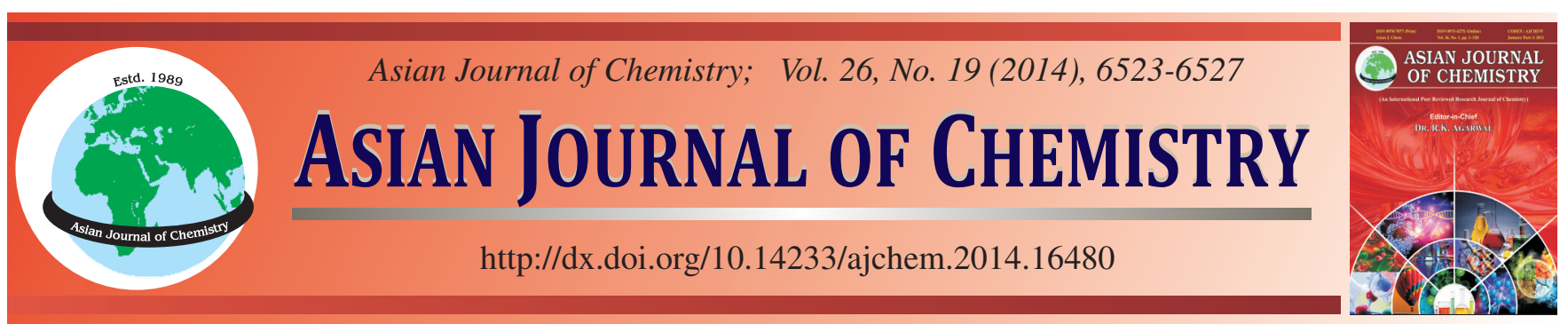

\title{
Characterization of Keratin Hydrolyzates Prepared from Sheep Wool
}

\author{
Pavel Mokrejș ${ }^{1,2, *}$, Ondrej Krejcí1, Svatopluk SukoP ${ }^{3}$ and Petr Svoboda ${ }^{1,2}$
}

${ }^{1}$ Department of Polymer Engineering, Faculty of Technology, Tomas Bata University in Zlin, nam. TGM 275, 76272 Zlin, The Czech Republic ${ }^{2}$ Centre of Polymer Systems, University Institute, Tomas Bata University in Zlin, Nad Ovcirnou 3685, 76001 Zlin, The Czech Republic ${ }^{3}$ Department of Chemistry, Faculty of Technology, Tomas Bata University in Zlin, nam. TGM 275, 76272 Zlin, The Czech Republic

*Corresponding author: Fax:+420 577210172; Tel: +420 576031230; E-mail: mokrejs@ft.utb.cz

\begin{abstract}
Preparation of keratin hydrolyzates through alkaline-enzymatic hydrolysis was already described earlier. Employment of hydrolyzates in practice requires knowledge of their composition, thermal stability and molecular weight. The aim of this contribution is to determine molecular weight of keratin hydrolyzates (prepared from sheep wool). Molecular weight $\left(\mathrm{M}_{\mathrm{w}}\right)$ of keratin hydrolyzates was determined by SDS-PAGE (sodium dodecyl sulphate polyacrylamide gel electrophoresis). Selection of hydrolysis conditions allows to prepare hydrolyzates with predominant share of low-molecular fractions $\left(\mathrm{M}_{\mathrm{w}}<10 \mathrm{kDa}\right)$, intermediate-molecular fractions $\left(\mathrm{M}_{\mathrm{w}} \approx 10-50 \mathrm{kDa}\right)$ or high-molecular fractions $\left(\mathrm{M}_{\mathrm{w}}>70 \mathrm{kDa}\right)$. Optimal conditions for preparing keratin hydrolyzates are as follows: in $1^{\text {st }}$ stage of hydrolysis, acting on wool with $0.6 \% \mathrm{KOH}$ at $90{ }^{\circ} \mathrm{C}$ for $48 \mathrm{~h}$; in $2^{\text {nd }}$ stage of hydrolysis, adding $1 \%(\mathrm{w} / \mathrm{w})$ proteolytic enzyme Savinase $6 \mathrm{~T}$ and stirring at $40{ }^{\circ} \mathrm{C}$ for $24 \mathrm{~h}$. Under these conditions, breakdown efficiency is $63 \%$ and a hydrolyzate is prepared containing $11.5 \% \mathrm{~N}, 14.9 \%$ ash, $2.58 \%$ sulphur and a high portion of intermediate- and high-molecular fractions which is comparable in quality to technical gelatine. Keratin hydrolyzate can be employed, for example, to produce wrapping materials (films, coatings, encapsulates).
\end{abstract}

Keywords: Hydrolysis, Hydrolyzate, Keratin, Molecular weight, Sheep wool.

\section{INTRODUCTION}

Keratins have a very rigid structure, particularly due to cross-linking with disulphide bonds that is highly resistant to action by chemicals and enzymes. In order to obtain soluble keratin (keratin hydrolyzates) it is mostly necessary to apply solutions of acids or alkalis in high concentrations under cooperation of high temperatures or pressure ${ }^{1,2}$. In enzymatic processing of keratin, it is appropriate to first pre-process keratin in an alkaline or acid environment or with oxidative or reducing agent. To achieve higher hydrolysis efficiency, more enzymes can be employed simultaneously ${ }^{3}$.

Keratin hydrolyzates have a wide spectrum of applications. When deciding about concrete use, it is essential to know data on composition of keratin hydrolyzates, their properties (for example, solubility, film-forming and rheological properties, thermal stability) and molecular weight.

Keratin hydrolyzates are often employed in agriculture as nitrogenous fertilizers and growth stimulants ${ }^{4,5}$. Hydrolyzates have a high nitrogen content (around $15 \%$ ) which makes them a high quality and inexpensive source of nitrogen. Moreover, they are biodegradable and preparation of hydrolyzates exhibiting different solubility allows to guide the dosage and release of nitrogen into soil ${ }^{6,7}$. Choice of suitable conditions in alkaline preparation of hydrolyzates, for example, hydrolysis in $\mathrm{KOH}$ environment followed by neutralisation with $\mathrm{H}_{3} \mathrm{PO}_{4}$, allows to prepare combined fertiliser also containing necessary potassic and phosphorous macro-ions ${ }^{8}$. Products of keratin splitting (hydrolyzates, powdered feed) can also be successfully applied in animal agro-production as feed-mix components. Owing to a high content of proteins and essential amino acids, they are suitable for complementing cattle and poultry feed $^{9-15}$.

Keratin hydrolyzates also find use in medicine, mainly for their similarity to human tissue. They are applied most when preparing films for tissue engineering when healing surface wounds (for example, chafes, burns) and as a substance supporting growth of new skin tissue ${ }^{16,17}$. Another medical application consists in making a composite material from polylactic acid and keratin and its utilization as frame for cultivating osteoblastsbone cells ${ }^{18}$. A widespread use is in water-soluble keratin hydrolyzates for cosmetics, where they are added to preparations for hair and skin care ${ }^{19}$. Keratin hydrolyzates may also be employed in foodstuffs industry for producing wrapping materials or encapsulates. They can also be used as additives when producing concrete and making ceramics ${ }^{20}$.

In our previous publications we dealt with preparing keratin hydrolyzates from sheep wool and poultry feathers 
through combined alkaline-enzymatic hydrolysis ${ }^{21-24}$. Use of hydrolyzates in practice mainly requires knowledge of their composition, thermal stability and molecular weight. Data on composition and thermal stability of hydrolyzates were shown in our publication ${ }^{25}$. The aim of the present contribution is to determine molecular weights $\left(\mathrm{M}_{\mathrm{w}}\right)$ of selected hydrolyzates. A further objective is to consider influence of technological conditions during hydrolyzate preparation on molecular weight of hydrolyzates. Finally, optimal conditions will be proposed for preparing keratin hydrolyzate with a view to efficiency of the whole process and its quality.

\section{EXPERIMENTAL}

Programmmable power supply Novex Model-3540 (USA), minicell Novex Xcell II (USA), Novex 10-20\% tricine polyacrylamide gel EC6625 (USA), spectrophotometer Helios Epsilon, rotating evaporator Hei-Vap G1, pH meter SensoDirect 110SET, magnetic stirrer MR Hei Standard, agitator PTFE 350/8 mm, water bath Memmert WNE 45 L1, analytical balances Denver Summit SI234, heating plate Schott Ceran 93020, drier WTB Binder E/B 28, incubator WTC Binder B53, mineralizing apparatus Hach Digesdahl, muffle furnace Nabertherm L 9/S 27, distilling apparatus according to Parnas-Wagner, refrigerator Samsung Calex C 180, Ubbelohde viscometer U II with capillary diameter $1.13 \mathrm{~mm}$ (the Czech Republic).

$\beta$-Mercaptoethanol (Sigma-Aldrich, USA, Cat. No. M7154), glacial acetic acid (Sigma-Aldrich, USA, Cat. No. A9967), Brilliant Blue G (Sigma-Aldrich, USA, Cat. No. B2025), ninhydrine (Sigma-Aldrich, USA, Cat. No. 724894), sodium acetate buffer solution (Sigma-Aldrich, USA, Cat. No. $\mathrm{S} 7899), \mathrm{SnCl}_{2} \cdot 2 \mathrm{H}_{2} \mathrm{O}$ (Sigma-Aldrich, USA, Cat. No. 243523). All other chemicals of analytical grade $\left(\mathrm{NaOH}, 96 \% \mathrm{H}_{2} \mathrm{SO}_{4}\right.$, $65 \% \mathrm{HNO}_{3}, \mathrm{H}_{3} \mathrm{BO}_{3}, 30 \% \mathrm{H}_{2} \mathrm{O}_{2}, \mathrm{BaCl}_{2}$ ) were supplied by Petr Lukes Co. (the Czech Republic). Catalyst for mineralizing (Kjeltabs KWS) was supplied by Thompson \& Capper Ltd. (Cheshire, USA). Novex Tricine SDS Buffer Kit (USA, Cat. No. LC1677). Ultra Low Range Molecular Weight Marker 1,060-26,600 Da (Sigma-Aldrich, USA, Cat. No. M3546). Wide Range Molecular Weight Marker 6,500-200,000 Da (Sigma-Aldrich, USA, Cat. No. S8445).

General procedure: Contents of nitrogen, ash and sulphur in hydrolyzates were determined according to standard methods ${ }^{26,27}$. Molecular weight $\left(\mathrm{M}_{\mathrm{w}}\right)$ of keratin hydrolyzates was performed by method SDS-PAGE (sodium dodecyl sulphate-polyacrylamide gel electrophoresis) on 10-20\% tricine polyacrylamide gel measuring $8.6 \times 8.1 \mathrm{~cm}$ at $\mathrm{pH} 8.3$ in minicell Novex Xcell II employing programmable power supply Novex Model-3540 under constant voltage $125 \mathrm{~V}$ and power intensity $80 \mathrm{~mA}$ at start and $40 \mathrm{~mA}$ at end. Before applying on polyacrylamide gel, hydrolyzates were dissolved (1:1) in buffer (Tricine SDS Buffer Kit: $30 \% 3 \mathrm{M}$ tris-HCl, 24 $\%$ glycerol, $8 \%$ SDS, $0.015 \%$ Coomassie Blue G, $0.005 \%$ Phenol Red, with added $2.5 \% \beta$-mercaptoethanol and distilled water) heated to $85 \pm 0.5^{\circ} \mathrm{C}$ for $2 \mathrm{~min}$. Amount of hydrolyzate applied into holes in polyacrylamide gel was $20 \mu \mathrm{L}$. Electrophoretic separation ended in approx $90 \mathrm{~min}$. When gel electrophoresis was finished, fractions in gel were fixed with a $7 \%$ solution of glacial acetic acid in $40 \%$ methanol (v/v) in $1 \mathrm{~h}$. Following detection of separated fractions was executed by colouring gel in blue colourant Brilliant Blue $\mathrm{G}$ dispersed in methanol aqueous solution (1.5 h). After colouring the gel, excess colourant was removed by immersing gel in $25 \%$ methanol solution (up to $24 \mathrm{~h}$ ).

Preparation of keratin hydrolyzates: The procedure for preparing keratin hydrolyzates from sheep wool through alkaline-enzymatic hydrolysis was presented in previous publications $^{21,22}$. A flow chart of hydrolyzate preparation is shown in Fig. 1. Survey of factor experiments for preparing keratin hydrolyzates, including efficiency of the hydrolytic process (yield of hydrolyzate), is given in Table-1. Conditions for preparing hydrolyzate are shortly given as follows:

Hydrolyzates I: Hydrolysis $1^{\text {st }}$ stage: $0.3 \% \mathrm{KOH}, 90{ }^{\circ} \mathrm{C}$, 48 h; hydrolysis $2^{\text {nd }}$ stage: $1-5 \%$ enzyme Savinase (Factor A), 40-60 ${ }^{\circ} \mathrm{C}$ (Factor B), 6-24 h (Factor C).

Hydrolyzates II: Hydrolysis $1^{\text {st }}$ stage: $0.5 \% \mathrm{Ca}(\mathrm{OH})_{2}$, $80{ }^{\circ} \mathrm{C}, 6-24 \mathrm{~h}$ (Factor A); hydrolysis $2^{\text {nd }}$ stage: $1-5 \%$ enzyme Esperase (Factor B), $60{ }^{\circ} \mathrm{C}, 6-24 \mathrm{~h}$ (Factor C).

Hydrolyzates III: Hydrolysis $1^{\text {st }}$ stage: 0.2-0.6\% $\mathrm{Ca}(\mathrm{OH})_{2}$ (Factor A), $40-80{ }^{\circ} \mathrm{C}$ (Factor B), 24 h; hydrolysis $2^{\text {nd }}$ stage: $5 \%$ enzyme Esperase, $40-60{ }^{\circ} \mathrm{C}$ (Factor C), $24 \mathrm{~h}$.

Hydrolyzates IV: Hydrolysis $1^{\text {st }}$ stage: $0.2-0.6 \% \mathrm{KOH}$ (Factor A), $90{ }^{\circ} \mathrm{C}, 48 \mathrm{~h}$; hydrolysis $2^{\text {nd }}$ stage: $1-5 \%$ enzyme Savinase (Factor B), $40-60{ }^{\circ} \mathrm{C}$ (Factor C), $24 \mathrm{~h}$.

Hydrolyzates V: Hydrolysis $1^{\text {st }}$ stage: $0.2-0.6 \% \mathrm{Ca}(\mathrm{OH})_{2}$ (Factor A), $40-80{ }^{\circ} \mathrm{C}$ (Factor B), $24 \mathrm{~h}$; hydrolysis $2^{\text {nd }}$ stage: 5 $\%$ enzyme Everlase, $40-60{ }^{\circ} \mathrm{C}$ (Factor C), $24 \mathrm{~h}$.

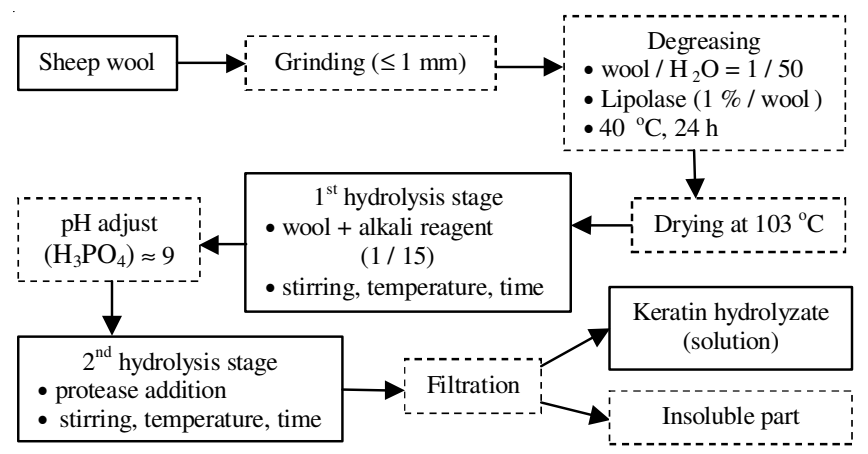

Fig. 1. Flow chart of processing sheep wool into keratin hydrolyzate

\section{RESULTS AND DISCUSSION}

Molecular weight $\left(\mathrm{M}_{\mathrm{w}}\right)$ of hydrolyzates affects their industrial applications. In order to study the effect of technological conditions on $\mathrm{M}_{\mathrm{w}}$ of prepared hydrolyzates (I-V), several hydrolyzates were always selected from the series of experiments. To evaluate quality of prepared hydrolyzates, their electrophoregrams were compared with those of two protein standards. Ultra Low Range Molecular Weight Marker 3546 contains 6 proteins of molecular weights ranging within 1,060-26,600 Da. Wide Range Molecular Weight Marker S8445 contains 12 proteins of molecular weights in limits 6,500-200,000 Da.

Fig. 2 indicates electrophoretic profiles of selected hydrolyzates prepared according to conditions I and II. Tracks 1 and 10 represent protein standards. Track 2 represents the electrophoregram of hydrolyzate II from experiment No. 1; hydrolyzate contains only low-molecular fractions, most in 


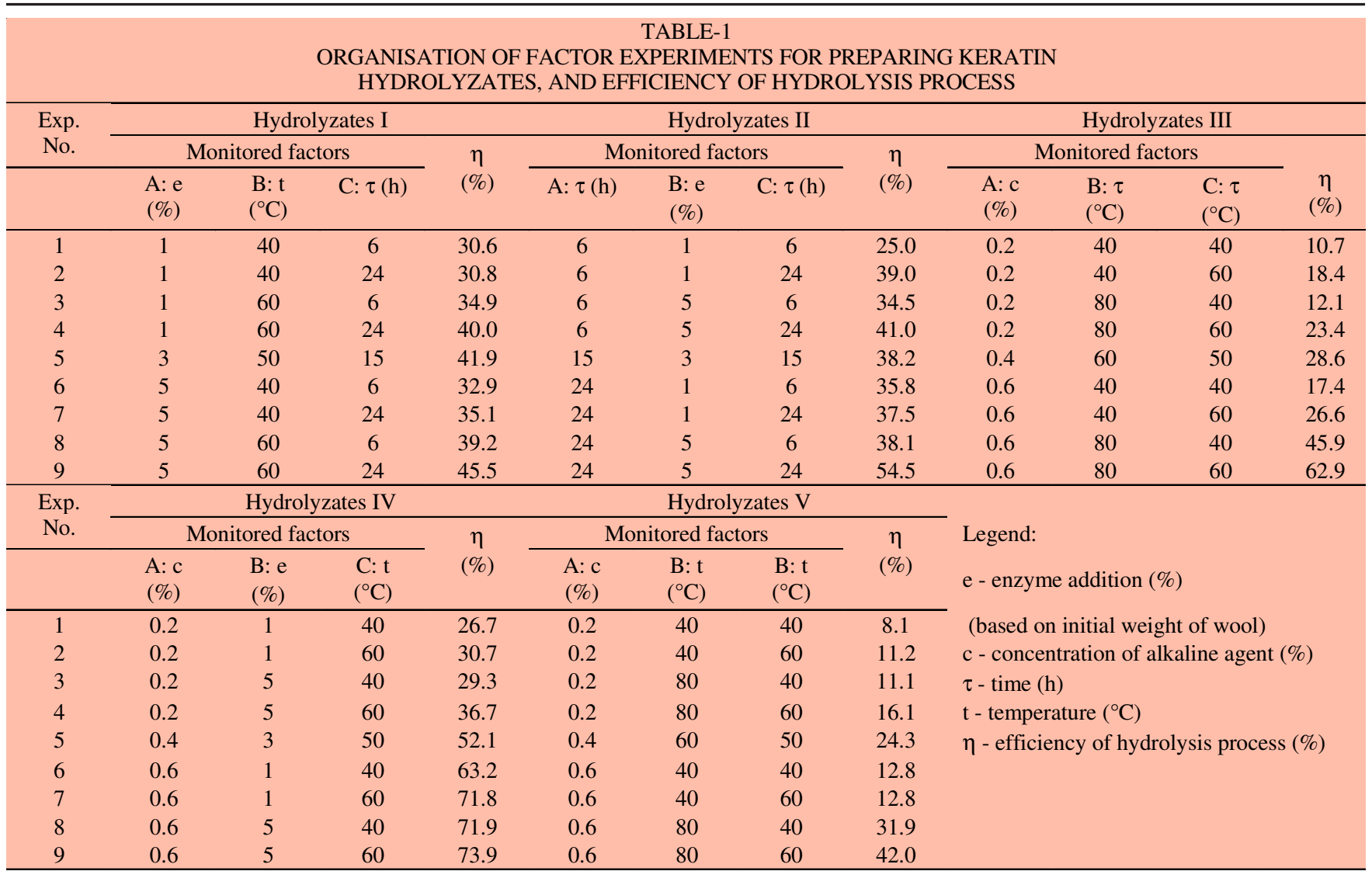

limits 3.5-17 kDa, intermediate and high-molecular fractions are almost absent. Very similar fractions Mw are seen with the same hydrolyzate from experiments No. 5 (track 4) and No. 9 (track 6) even though these two hydrolyzates display a certain presence of fractions up to $97 \mathrm{kDa}$. Hydrolyzates II prepared from experiments No. 3 (track 3) and No. 7 (track 5) have $\mathrm{Mw}$ fractions that are very wide. They mostly contain lowmolecular fractions ranging from 3.5 to $20 \mathrm{kDa}$, nevertheless, here are also obvious fractions ranging from 20 to $97 \mathrm{kDa}$ and even a small part of high-molecular fractions exceeding 100 kDa. Hydrolyzates I represented by experiments Nos. 4, 5 and

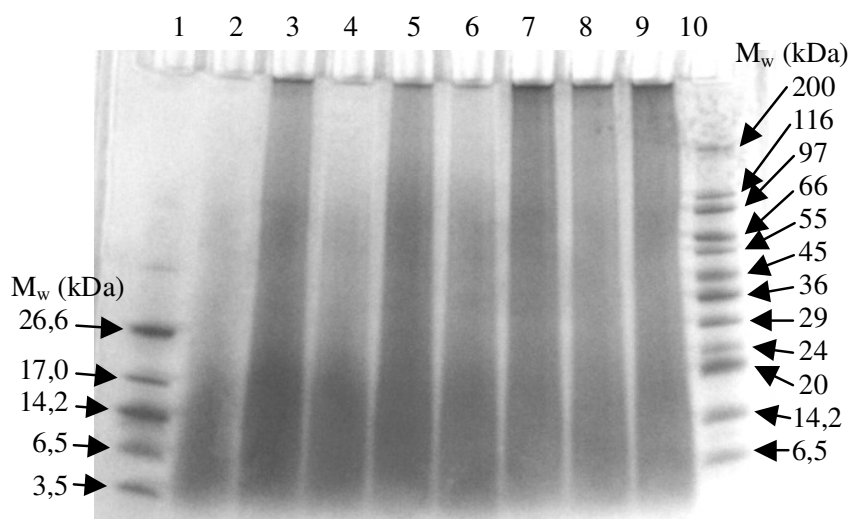

Fig. 2. SDS-PAGE electrophoregram of selected keratin hydrolyzates prepared in accordance with conditions I and II and protein standards; track: 1-ultra low range molecular weight Marker (3,526,6 kDa), 2-hydrolyzate II/exp. No. 1, 3-hydrolyzate II/exp. No. 3, 4-hydrolyzate II/exp. No. 5, 5-hydrolyzate II/exp. No. 7, 6hydrolyzate II/exp. No. 9, 7-hydrolyzate I/ exp. No. 4, 8-hydrolyzate I/exp. No. 5, 9-hydrolyzate I/exp. No. 6, 10-wide range molecular weight Marker $(6,5-200 \mathrm{kDa})$
6 (tracks 7, 8 and 9) also display a very wide range of $M_{w}$ fractions. All fractions are present, most are low-molecular (up to $24 \mathrm{kDa}$ ). It is interesting that especially hydrolyzate I prepared according to experiment No. 4 (track 7) contains quite a strong portion of fractions ranging from 45 to $97 \mathrm{kDa}$.

Electrophoretic profiles are in Fig. 3 indicating selected hydrolyzates prepared in accordance with conditions III and V. Electrophoregram of hydrolyzate III from experiment No. 2 is indicated on track 2 and it is clearly obvious that merely lowest $\mathrm{M}_{\mathrm{w}}$ fractions (below $6.5 \mathrm{kDa}$ ) are present. The same hydrolyzates from experiments Nos. 3 and 4 (tracks 3 and 4) exhibit greatest proportion of low-molecular fractions $\left(\mathrm{M}_{\mathrm{w}}\right.$ up

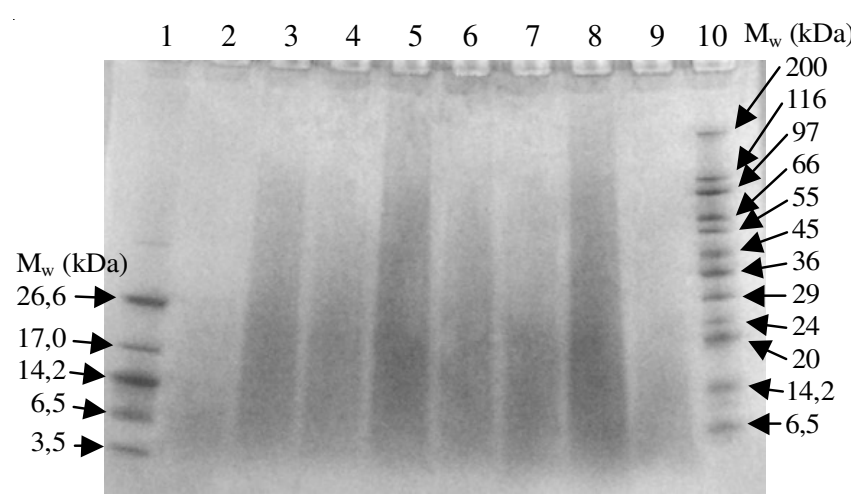

Fig. 3. SDS-PAGE electrophoregram of selected keratin hydrolyzates prepared in accordance with conditions III and V and protein standards; track: 1-ultra low range molecular weight Marker (3,526,6 kDa), 2-hydrolyzate III/exp. No. 2, 3-hydrolyzate III/exp. No. 3, 4-hydrolyzate III/exp. No. 4, 5-hydrolyzate III/exp. No. 5, 6hydrolyzate III/exp. No. 6, 7-hydrolyzate III/exp. No. 7, 8hydrolyzate III/exp. No. 8, 9-hydrolyzate V/exp. No. 5, 10-wide range molecular weight Marker (6,5-200 kDa) 
to $26 \mathrm{kDa}$ ); intermediate-molecular fractions are represented very slightly. A similar situation concerning $\mathrm{M}_{\mathrm{w}}$ appears with hydrolyzates from experiments Nos. 6 and 7 (tracks 6 and 7). Hydrolyzates III from experiments Nos. 5 and 8 (tracks 5 and 8) show wider $M_{w}$ fractions; most represented are again the low-molecular fractions but these also contain, as opposed to previous hydrolyzates, a greater portion of intermediate-molecular fractions $(29-66 \mathrm{kDa})$ and even small proportions of fractions above $66 \mathrm{kDa}$ are present. Track 9 represents hydrolyzate V from experiment No. 5 and solely low-molecular fractions $\left(M_{w}<14 \mathrm{kDa}\right)$ are present here.

Fig. 4 indicates electrophoretic profiles of selected hydrolyzates prepared in accordance with conditions III, IV and V. With hydrolyzates prepared in accordance with conditions IV of experiments Nos. 4, 5 and 6 (tracks 2, 3 and 4) the $M_{w}$ fractions are very wide. Lowest fractions (below $20 \mathrm{kDa}$ ) are represented here as well as intermediate fractions (20-66 kDa) and also high-molecular fractions $\left(\mathrm{M}_{\mathrm{w}}>97 \mathrm{kDa}\right)$. Especially with hydrolyzate from experiment No. 6 (track 4) there is an obvious proportion of high-molecular fractions; hydrolyzate thus prepared, from the viewpoint of $\mathrm{M}_{\mathrm{w}}$ distribution, is highest quality of all prepared hydrolyzates. Hydrolyzates prepared in accordance with conditions $\mathrm{V}$ of experiments Nos. 4, 6 and 9 (tracks 5, 6 and 7) display strongly different $M_{\mathrm{w}}$ fractions. While hydrolyzate prepared according to experiment No. 6 (track 6) shows only lowest fractions $\left(\mathrm{M}_{\mathrm{w}}<6.5 \mathrm{kDa}\right)$, hydrolyzate No. 9 (track 7) also has intermediate-molecular fractions (24-66 kDa). Electrophoregram of hydrolyzate $\mathrm{V}$ from experiment No. 4 (track 5) displays the widest $\mathrm{M}_{\mathrm{w}}$ fractions with low content of fractions from 16 to $116 \mathrm{kDa}$. Hydrolyzates III / experiment No. 1 (track 8) and IV / experiment No. 9 (track 9) contain low-molecular fractions $\left(\mathrm{M}_{\mathrm{w}}\right.$ below $\left.26 \mathrm{kDa}\right)$.

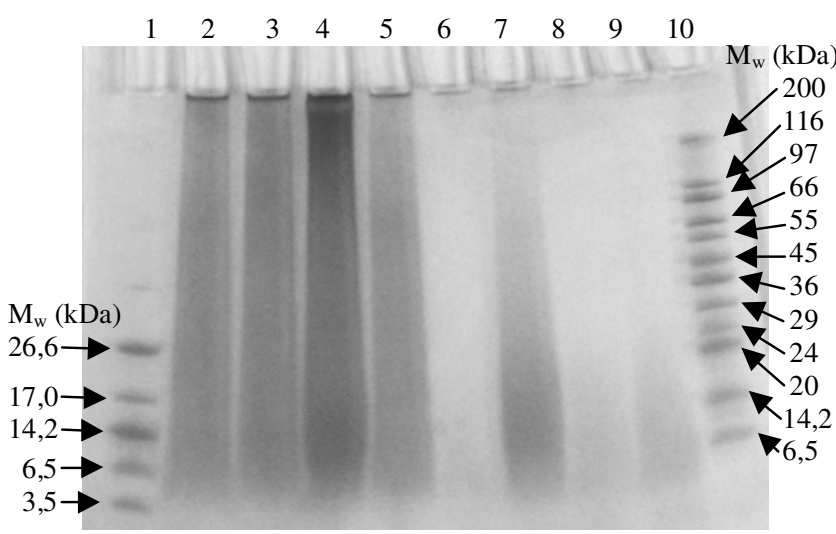

Fig. 4. SDS-PAGE electrophoregram of selected keratin hydrolyzates prepared in accordance with conditions III, IV and V and protein standards; track: 1-ultra low range molecular weight Marker (3,526,6 kDa), 2-hydrolyzate IV/exp. No. 4, 3-hydrolyzate IV/exp. No. 5, 4-hydrolyzate IV/exp. No. 6, 5-hydrolyzate V/exp. No. 4, 6hydrolyzate V/exp. No. 6, 7-hydrolyzate V/exp. No. 9, 8-hydrolyzate III/exp. No. 1, 9-hydrolyzate IV/exp. No. 9, 10-wide range molecular weight Marker (6,5-200 kDa)

Optimal conditions for preparing keratin hydrolyzates: Proposed optimal conditions for preparing keratin hydrolyzates were based on results of hydrolyzate molecular weights. Hydrolyzates selected from each series of experiments contained greatest proportion of intermediate- or high-molecular fractions.
From hydrolyzates prepared in accordance with conditions I, greatest presence of intermediate- and high-molecular fractions $\left(\mathrm{M}_{\mathrm{w}}=24-97 \mathrm{kDa}\right.$, partly even above $\left.97 \mathrm{kDa}\right)$ is found with hydrolyzate prepared according to experiment No. 4 (see Fig. 2 track 7). Air-dry hydrolyzate contains $10.3 \%$ N, $13.8 \%$ ash and $2.25 \%$ sulphur. From hydrolyzates prepared in accordance with conditions II, greatest presence of intermediatemolecular fractions $\left(\mathrm{M}_{\mathrm{w}}=24-97 \mathrm{kDa}\right)$ is found with hydrolyzate prepared according to experiment No. 7 (Fig. 2-track 5). Air-dry hydrolyzate contains $11 \%$ N, $15.3 \%$ ash and $3.24 \%$ sulphur. From hydrolyzates prepared in accordance with conditions III, greatest presence of intermediate-molecular fractions $\left(\mathrm{M}_{\mathrm{w}}=29-66 \mathrm{kDa}\right)$ is found with hydrolyzate prepared according to experiment No. 8 (Fig. 3-track 8). Air-dry hydrolyzate contains $11.1 \% \mathrm{~N}, 24.3 \%$ ash and $2.98 \%$ sulphur. From hydrolyzates prepared in accordance with conditions IV, greatest presence of intermediate-molecular fractions (29$97 \mathrm{kDa})$ and high-molecular fractions $\left(\mathrm{M}_{\mathrm{w}}>97 \mathrm{kDa}\right)$ is found with hydrolyzate prepared in accordance with experiment No. 6 (Fig. 4-track 4). Air-dry hydrolyzate contains $11.5 \%$ N, $14.9 \%$ ash and $2.58 \%$ sulphur. From hydrolyzates prepared in accordance with conditions $\mathrm{V}$, greatest presence of intermediate-molecular fractions $\left(\mathrm{M}_{\mathrm{w}}=29-66 \mathrm{kDa}\right)$ and small presence of fractions from 66 to $116 \mathrm{kDa}$ is found with hydrolyzate prepared in accordance with experiment No. 4 (Fig. 4track 5). Air-dry hydrolyzate contains $9.9 \%$ N, $26.1 \%$ ash and $4.1 \%$ sulphur.

Reduction of ash content in hydrolyzates, which is essential for some applications, may, for example, utilise dialysis or ion exchangers ${ }^{28}$. Dialysis of keratin hydrolyzates was dealt with in our previous contribution ${ }^{29}$.

\section{Conclusion}

Molecular weight of keratin hydrolyzates prepared from sheep wool through 2-stage alkaline-enzymatic hydrolysis under various conditions (choice and concentration of alkaline environment, temperature and duration in $1^{\text {st }}$ and $2^{\text {nd }}$ hydrolysis stage, addition of enzyme) was determined through gel electrophoresis (SDS-PAGE). It was confirmed that technological conditions in hydrolyzate preparation exert strong influence both on hydrolysis efficiency and hydrolyzate composition as well as strongly affecting the fractions of hydrolyzate molecular weights. Convenient choice of alkaline environment and hydrolysis conditions allows to prepare hydrolyzates with prevalent proportion of low-molecular fractions $\left(M_{w}<10 \mathrm{kDa}\right)$, intermediate-molecular fractions $\left(\mathrm{M}_{\mathrm{w}} \approx 10-50 \mathrm{kDa}\right)$ and also hydrolyzates with which high-molecular fractions $\left(\mathrm{M}_{\mathrm{w}}>90 \mathrm{kDa}\right)$ are present. Hydrolyzates with a proportion of intermediate- and high-molecular fractions are comparable in quality to technical gelatines and could be employed, for example, to produce wrapping materials (films, coatings, encapsulates).

Optimal conditions for preparing keratin hydrolyzate are as follows: In $1^{\text {st }}$ hydrolysis stage, reacting wool with $0.6 \%$ $\mathrm{KOH}$ at $90{ }^{\circ} \mathrm{C}$ for $48 \mathrm{~h}$, in $2^{\text {nd }}$ hydrolysis stage, adding $1 \%$ (w/ w) proteolytic enzyme Savinase 6.0T (Novozymes, Denmark) and stirring $24 \mathrm{~h}$ at $40{ }^{\circ} \mathrm{C}$. Under these conditions, breakdown efficiency is $63 \%$ and a hydrolyzate is prepared containing a high proportion of intermediate- and high-molecular fractions. 


\section{ACKNOWLEDGEMENTS}

This article was written with support of Operational Program Research and Development for Innovations cofunded by the European Regional Development Fund (ERDF) and national budget of Czech Republic, within the framework of project Centre of Polymer Systems (reg. No.: CZ.1.05/ 2.1.00/03.0111).

\section{REFERENCES}

1. M.A. Meyers, P.Y. Chen, A.Y.M. Lin and Y. Seki, Progr. Mater. Sci., 53, 1 (2008).

2. M. Zoccola, A. Aluigi and C. Tonin, J. Mol. Struct., 938, 35 (2009).

3. W. Simpson and G. Crawshaw, Wool: Science and Technology, Woodhead Publ., Cambridge (2002).

4. A. Grazziotin, F.A. Pimentel, S. Sangali, E.V. deJong and A. Brandelli, Bioresour. Technol., 98, 3172 (2007).

5. A. Vesela and M.J. Friedrich, Biotechnol. Bioproc. Eng., 14, 84 (2009).

6. G. Coward-Kelly, F.K. Agbogbo and M.T. Holtzapple, Bioresour. Technol., 97, 1344 (2006).

7. R. Gupta and P. Ramnani, Appl. Microbiol. Biotechnol., 70, 21 (2006).

8. A. Gousterova, M. Nustorova, I. Goshev, P. Christov, D. Braikova, K. Tishinov, T. Haertle and P. Nedkov, Biotechnol. Biotechnol. Equip., 17, 140 (2003)

9. A.A. Khardenavis, A. Kapley and J. Purohit, Waste Manage., 29, 1409 (2009).

10. A. Grazziotin, F.A. Pimentel, E.V. deJong and A. Brandelli, Anim. Feed Sci. Technol., 126, 135 (2006).
11. A.A. Onifade, N.A. Al-Sane, A.A. Al-Musallam and S. Al-Zarban, Bioresour. Technol., 66, 1 (1998).

12. V.D. Zheljazkov, G.W. Stratton, J. Pincock, S. Butler, E.A. Jeliazkova, N.K. Nedkov and P.D. Gerard, Waste Manage., 29, 2160 (2009).

13. P. Dalev, I. Ivanov and A. Liubomirova, J. Sci. Food Agric., 73, 242 (1997).

14. A. Bertsch and N. Coello, Bioresour. Technol., 96, 1703 (2005).

15. N.H. Odetallah, J.J. Wang, J.D. Garlich and J.C.H. Shih, Poult. Sci., 82, 664 (2003).

16. S. Reichl, Biomaterials, 30, 6854 (2009).

17. X. Yang, H. Zhang, X. Yuan and S. Cui, J. Colloid Interf. Sci., 336, 756 (2009).

18. J. Li, Y. Li, L. Li, A.F.T. Mak, F. Ko and L. Qin, Composites B, 40, 664 (2009).

19. G. Secchi, Clin. Dermatol., 26, 321 (2008).

20. R. Karthikeyan, S. Balaji and P.K. Sehgal, J. Sci. Ind. Res. (India), 66, 710 (2007).

21. P. Mokrejs, O. Krejci, P. Svoboda and V. Vasek, Rasayan J. Chem., 4, 728 (2011)

22. P. Mokrejs, O. Krejci and P. Svoboda, Oriental J. Chem., 27, 1303 (2011).

23. P. Mokrejs, P. Svoboda, J. Hrncirik, D. Janacova and V. Vasek, Waste Manage. Res., 29, 260 (2011).

24. P. Mokrejs, J. Hrncirik, D. Janacova and P. Svoboda, Asian J. Chem., 24, 1489 (2012).

25. O. Krejci and P. Mokrejs, Waste Forum, 1, 35 (2010).

26. AOAC, 935.46, Gelatin-Ash, Moisture, Nitrogen (1998).

27. AOAC 955.48, Microchemical Determination of Sulfur (1998).

28. J.A. Arnesen and A. Gildberg, Bioresour. Technol., 98, 53 (2007).

29. O. Krejci and P. Mokrejs, Waste Forum, 4, 216 (2012). 